\title{
Effects of Various Dietary Cholesterol Levels on Serum Tocopherol and Fatty Acid Composition in Female Rats
}

\author{
Kazuko Hirai, ${ }^{1,}$ * Masako Matsushita, ${ }^{1}$ Miwako Namiki, ${ }^{1}$ \\ and Hisako Hotta-Hara ${ }^{2}$ \\ ${ }^{1}$ Department of Nutritional Biochemistry, Faculty of the Science of Living, \\ Osaka City University, Sumiyoshi-ku, Osaka 558, Japan \\ ${ }^{2}$ Department of Bacteriology, Osaka City University Medical School, \\ Abeno-ku, Osaka 545, Japan
}

(Received August 2, 1987)

\begin{abstract}
Summary The effect of dietary cholesterol $(0-1 \%)$ on the levels of serum cholesterol, vitamin E (tocopherol), and fatty acid composition was determined in female rats fed a $10 \%$ butter diet with $10 \mathrm{mg} \%$ tocopherol. When the dietary cholesterol level was increased, serum cholesterol and tocopherol also increased ( $r=0.72$ and $r=0.64$, respectively), and a direct relationship was found between the concentrations of serum cholesterol and tocopherol $(r=0.97)$. An increase in dietary cholesterol decreased the ratio of serum tocopherol to cholesterol $(r=-0.80)$. Elevated dietary cholesterol caused an increase in serum total fatty acid $(r=0.64)$ due to increases in saturated fatty acid (SFA, $r=0.63$ ) and monounsaturated fatty acid (MUFA, $r=0.67$ ), but no significant changes were found in the level of polyunsaturated fatty acid (PUFA, $r=0.22$ ). The ratios of PUFA/ SFA and PUFA/MUFA decreased with an increase in dietary cholesterol $(r=-0.82$ and $r=-0.81$, respectively). A direct relationship was found between the ratios of tocopherol/cholesterol and PUFA/SFA in serum $(r=0.77)$. These results indicate that dietary cholesterol affects vitamin $\mathrm{E}$ status and fatty acid composition of serum and that it has a detrimental effect on the ratios of tocopherol/cholesterol and PUFA/SFA in serum.
\end{abstract}

Key Words: dietary cholesterol, tocopherol status, fatty acid status, tocopherol/cholesterol, polyunsaturated fatty acid/saturated fatty acid

The level of serum cholesterol, a risk factor for coronary artery disease [1, 2], changes in response to dietary cholesterol [3, 4] and is correlated with the consumption of fat [5]. Dietary polyunsaturated fat [6-8] and a high dietary PUFA/

*To whom correspondence should be addressed. 
SFA ratio $[7,9,10]$ have been found to have serum cholesterol-lowering effects. Thus, dietary cholesterol and fatty acids influence the cholesterol metabolism. On the other hand, addition of $1 \%$ cholesterol to a $20 \%$ butter diet induced changes in the fatty acid composition of serum and a decrease in the PUFA/SFA ratio as we reported previously [11]. Although the mechanism is not known, dietary cholesterol seems to affect the fatty acid metabolism. A low-fat, low-cholesterol diet induces a decrease in plasma tocopherol and cholesterol levels [12]. It has been well established that the cholesterol level in plasma is closely related to the plasma tocopherol level [13-15]. Because of concomitant changes in the serum tocopherol level in proportion to the amounts of cholesterol or to total lipids in serum, the ratio of tocopherol to cholesterol and total lipids in the serum has been proposed to be a more precise assessment of the status of tocopherol than the serum tocopherol level [16]. When a single oral dose of vitamin $\mathrm{E}$ is administered to vitamin E-deficient rats, a high vitamin $\mathrm{E} /$ cholesterol ratio in plasma results [17]. However, the effect of dietary cholesterol on serum tocopherol level is not clearly known. The present work was undertaken to examine the response of female rats to the dietary cholesterol level $(0,0.25,0.50,0.75$, and $1.00 \%)$ in terms of the tocopherol and fatty acid composition of their serum. Also studied were the relationships between the serum tocopherol/cholesterol ratio and dietary cholesterol and between that ratio and the ratio of PUFA/SFA in serum.

\section{EXPERIMENTAL PROCEDURE}

Animals. Five groups of four female rats each (weighing 175 to $187 \mathrm{~g}$, Clea, Tokyo) were given experimental diets ad libitum for 18 days and the fasted 17-20 h prior to autopsy. The rats were anesthetized with ethyl ether, and then blood was collected through the abdominal aorta with a syringe and centrifuged to separate the serum.

Diets. The basal diet consisted of $10 \%$ butter (Snow Brand Milk Products Co., Tokyo), 20\% casein, 4\% Harper salt mixture [18], 1\% Harper vitamin mixture [18], $10 \mathrm{mg} \% \alpha$-tocopherol, $0.15 \%$ choline chloride, and sucrose to $100 \%$ with retinyl palmitate and cholecalciferol $(2,000$ and $1,000 \mathrm{IU}$ per $100 \mathrm{~g}$ diet, respectively). The test diets contained 0 to $1 \%$ cholesterol and cholic acid amounting to $25 \%$ of the cholesterol amount of the diet with a proportionate reduction in the amount of sucrose.

Preparation and analysis of cholesterol and fatty acids in serum. Saponification of serum and preparation of sterol and fatty acid fractions were carried out according to standard methods of the Japan Oil Chemists' Society for Analysis of Fats and Oils [19]. Cholesterol and fatty acids were analyzed by GLC as reported previously [20] with the following modification. The sterol fraction was loaded on a 1-m glass column packed with $3 \%$ OV-1 coated on 100-120 mesh Gaschrom Q (Gasukuro Kogyo, Tokyo) at a column temperature of $250^{\circ} \mathrm{C}$ with nitrogen as the carrier gas $(40 \mathrm{ml} / \mathrm{min})$. Fatty acid methyl esters were analyzed using a column 
packed with 5\% Silar-5CP on 80-100 mesh Uniport H.P (Gasukuro Kogyo, Tokyo). The temperature was programmed to rise from $210^{\circ} \mathrm{C}$ to $250^{\circ} \mathrm{C}$ at $3^{\circ} \mathrm{C}$ per min. The carrier gas (nitrogen) flow rate was $20 \mathrm{ml} / \mathrm{min}$. The contents of cholesterol and fatty acids were corrected on the basis of the recovery of the added internal standard of $5 \alpha$-cholestane and heptadecanoic acid $(17: 0)$, respectively.

Determination of tocopherol in serum. Tocopherol in serum was extracted by the method of Abe and Katsui [21], followed by separation by high-performance liquid chromatography (633A-FL203, Hitachi, Tokyo) on a Diasil $5 \mathrm{NH}_{2}$ column (4 mm i.d. $\times 250 \mathrm{~mm}$ ) (Nihon Chromato Works, Tokyo) with isopropanol in hexane $(0.6: 100)$ as the mobile phase. The amounts of tocopherol were measured fluorometrically (excitation, $298 \mathrm{~nm}$; emission, $325 \mathrm{~nm}$ ) and calculated from the recovery of the added internal standard of 2,2,5,7,8-pentamethyl 6-hydroxy chroman.

Statistical analysis. Data were analyzed by Student's $t$ test.

\section{RESULTS AND DISCUSSION}

As shown in Table 1, the serum cholesterol increased 7.8 -fold when the dietary cholesterol was raised from 0 to $1 \%(r=0.72)$. Therefore, it seems that up to $1 \%$ dietary cholesterol may not alter the rate of cholesterol absorption from the gastrointestinal tract or the rate of endogenous cholesterol synthesis in the body. The increase of serum cholesterol was correlated with the dietary cholesterol from a relatively low $(0.25 \%)$ to high $(1 \%)$ amount also suggesting that hypercholesterolemia induced by dietary cholesterol may be independent of a feedback mechanism for the control of cholesterol synthesis. If such a feedback control exists, it appears that it can be overcome by the administration of cholesterol.

The serum tocopherol concentration increased with increasing of dietary cholesterol with a 2.4 -fold increase at $1.00 \%(r=0.64)$, in spite of the fact that the same amount of tocopherol $(10 \mathrm{mg} \%$ ) was present in each diet (Table 1). Serum tocopherol levels were directly related to the serum cholesterol levels (Fig. 1, $r=$ 0.97). Because the cholesterol levels in diet and serum cause changes in the serum tocopherol level, it seems that the state of tocopherol nutrition should not be estimated only from the serum tocopherol level, especially when the serum cholesterol level is high. Horwitt et al. [16] proposed that the determination of nutrition adequacy of tocopherol was determined by using the ratio of tocopherol to lipid, such as cholesterol, triglyceride and phospholipids, in serum. As shown in Table 1 , the ratio of tocopherol/cholesterol in serum decreased as a function of increasing dietary cholesterol in spite of both levels of tocopherol and cholesterol in serum increasing with an increase of the dietary cholesterol. This result clearly shows that dietary cholesterol has a dose-dependent effect on the ratio of serum tocopherol/ cholesterol, and supports the ratio of tocopherol/cholesterol as a more precise assessment of tocopherol status. At the same time, it seems that a higher intake of cholesterol requires a higher intake of tocopherol to keep the serum tocopherol/ cholesterol level higher. 
K. HIRAI et al.

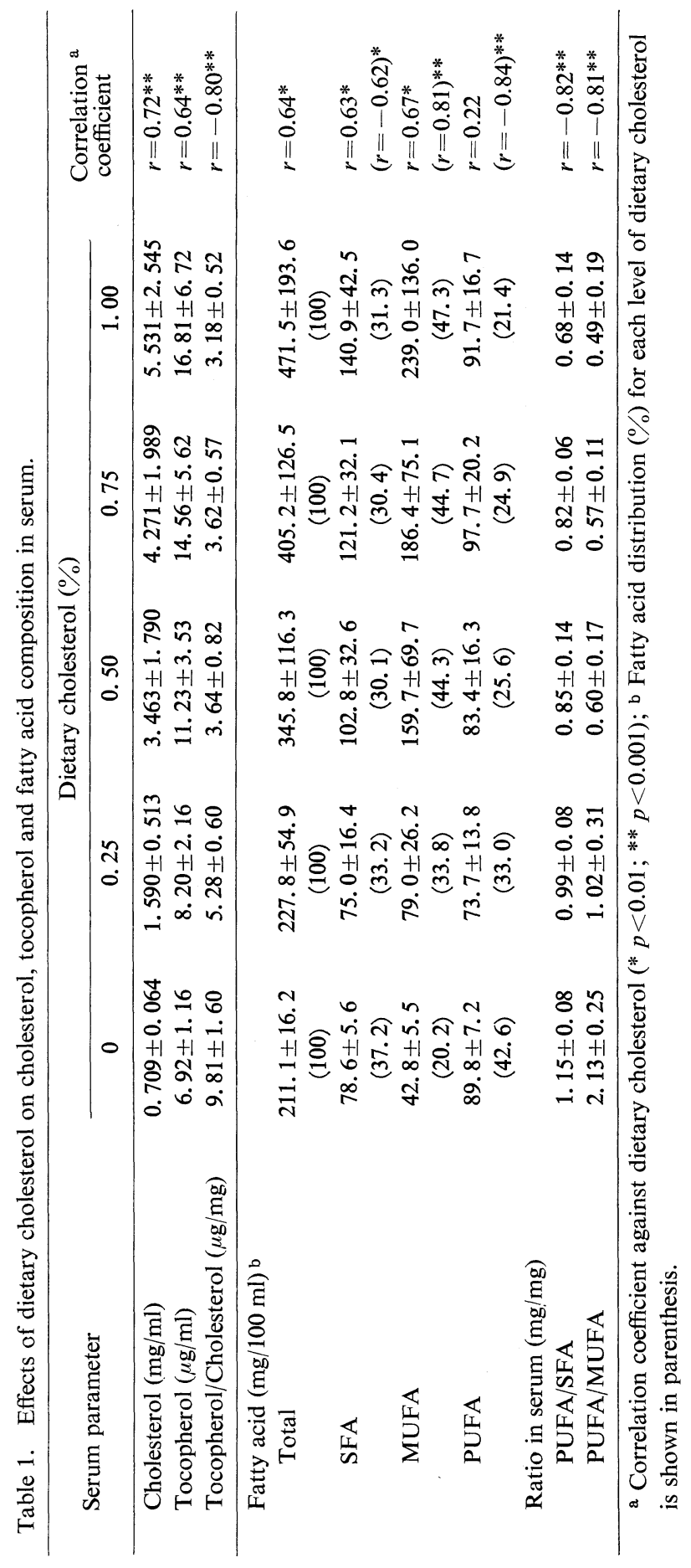

J. Clin. Biochem. Nutr. 


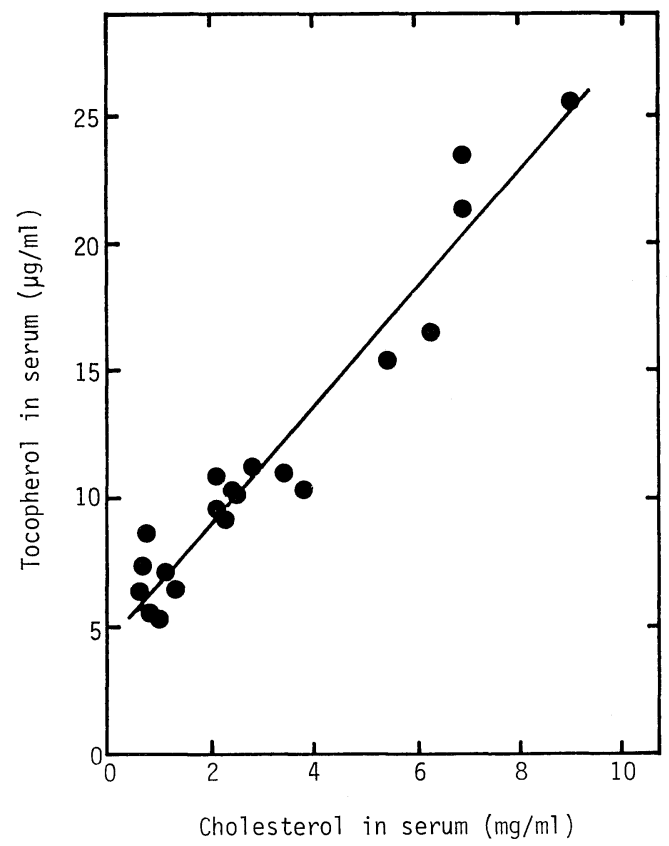

Fig. 1. Relationship between cholesterol and tocopherol levels in sera from individual rats fed various amounts of dietary cholesterol $(r=0.97, p<0.001)$.

The effects of various dietary cholesterol levels on fatty acid composition in serum were also assessed (Table 1). The levels of total fatty acid, SFA, and MUFA in serum increased 2.2-fold ( $r=0.64), 1.8$-fold $(r=0.63)$, and 5.6-fold $(r=0.67)$, respectively, with $1.00 \%$ dietary cholesterol while the level and composition of dietary fat $(10 \%$ butter) remained the same in all rats. The $75 \%$ increase in total fatty acid was due to an increase in MUFA and the $24 \%$ increase was due to an increase in SFA. There were no significant changes in the PUFA levels due to changes in the dietary cholesterol $(r=0.22)$. The composition of serum fatty acid changed with an increase in MUFA from $20.2 \%$ to $47.3 \%(r=0.81)$ and decreases in SFA and PUFA from $37.2 \%$ to $31.3 \%(r=-0.62)$ and from $42.6 \%$ to $21.4 \%$ $(r=-0.84)$, respectively. The ratio of PUFA/MUFA dropped more markedly, to one-fourth $(r=-0.81)$ of its value at $0 \%$ dietary cholesterol, than the PUFA/SFA ratio, which decreased to three-fifths $(r=-0.82)$. Thus, the changes in the levels and composition of fatty acid in serum were dependent on the dose of dietary cholesterol. These results indicate that dietary cholesterol affects the synthesis of fatty acids and thus the level and composition of fatty acids in serum, resulting in essential fatty acids deficiency, which can be explained by an increase in the MUFA level and decrease in the PUFA/SFA ratio [22]. The ratio of PUFA/MUFA offers a better representation of the effect of dietary cholesterol on the metabolism of 
fatty acids, which suggests that it could be used like the PUFA/SFA ratio, as an indicator of essential fatty acid deficiency caused by dietary cholesterol.

The increases in serum total fatty acid, SFA, and MUFA due to increased dietary cholesterol were correlated with an increase in serum cholesterol $(r=0.98$, $r=0.97$, and $r=0.98$, respectively). The level of PUFA in serum also showed a positive correlation with the serum cholesterol level $(r=0.67)$, but not with the amount of dietary cholesterol, as described above (Table $1, r=0.22$ ). These findings indicate that the metabolism of PUFA in serum is not directly affected by dietary cholesterol, but is related to the serum cholesterol level.

As shown in Fig. 2, oleic acid (18:1) and linoleic acid (18:2), main components of MUFA and PUFA, respectively, in serum, displayed relationships to serum total cholesterol, with oleic acid showing a more marked rate of change. Thus, at higher levels of serum cholesterol, deficiencies can be expected in the essential fatty acids, which can be explained by large portions with oleic acid and small portions with linoleic acid [22]. The correlation of serum cholesterol levels with the oleic acid level $(r=0.97)$ agrees with previous results from studies on the effects of dietary fats and phytosterol with the $1 \%$ cholesterol supplement to the

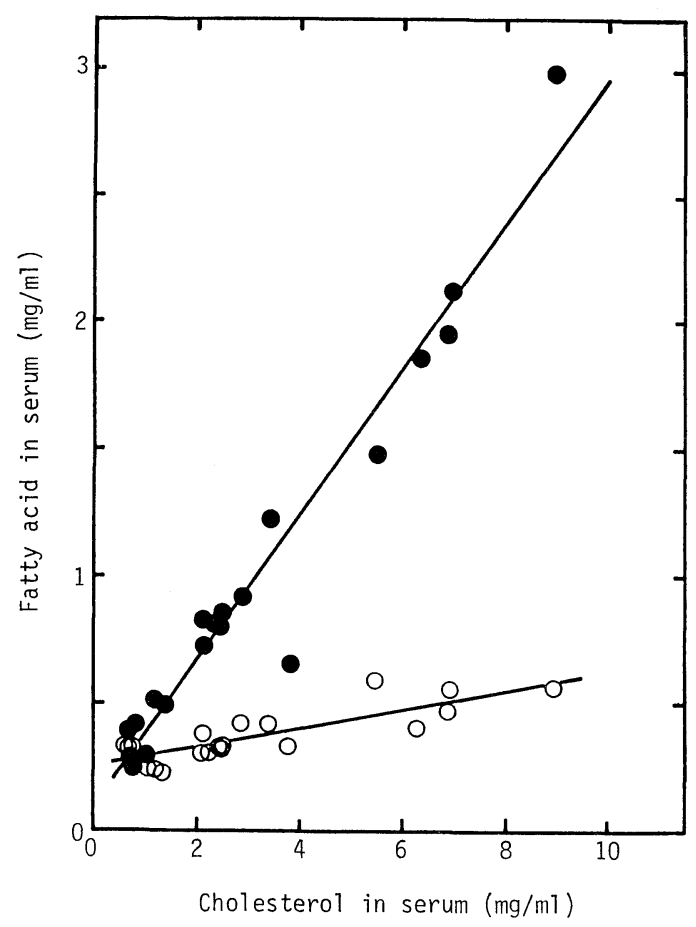

Fig. 2. Relationship between cholesterol and fatty acid levels in sera from individual rats fed various amounts of dietary cholesterol. Oleic acid, $\bullet(r=0.97, p<0.001)$; linoleic acid, $\bigcirc(r=0.86, p<0.001)$. 


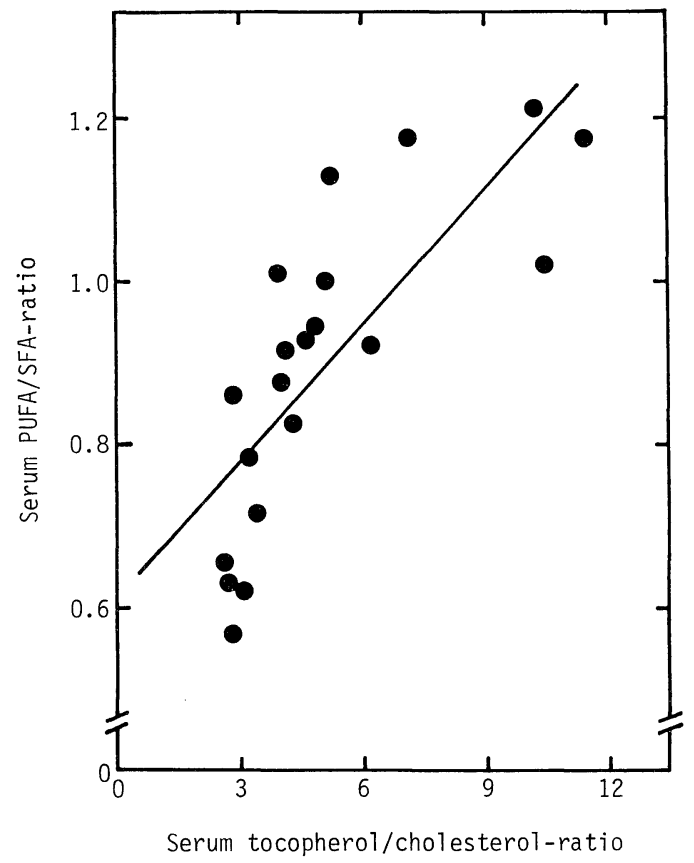

Fig. 3. Relationship of the ratios of tocopherol/cholesterol $(\mu \mathrm{g} / \mathrm{mg})$ and PUFA./SFA $(\mathrm{g} / \mathrm{g})$ in $\operatorname{serum}(r=0.77, p<0.001)$.

diet [11]. Therefore, these correlations not only depend on the dietary cholesterol level but also are a reflection of the results from the cholesterol metabolism affected by dietary fats and phytosterol.

As described above, dietary cholesterol affected the ratios of tocopherol/ cholesterol and PUFA/SFA in serum. As shown in Fig. 3, an increase in tocopherol/ cholesterol was correlated with an increase in PUFA/SFA $(r=0.77)$. Our findings indicate that the nutritional status of vitamin $\mathrm{E}$ and fatty acid composition are affected not only by dietary tocopherol and fats but also by cholesterol intake and that both ratios of tocopherol/cholesterol and PUFA/SFA are detrimentally affected by an increase in dietary cholesterol.

\section{REFERENCES}

1. Keys, A. (ed.) (1970): Coronary heart disease in seven countries. Circulation, Suppl. 1, 4142

2. Kannel, W.B., Castelli, W.P., Gordon, T., and McNamara, P.M. (1971): Serum cholesterol, lipoproteins, and the risk of coronary heart disease. The Framingham study. Ann. Intern. Med., 74, 1-12.

3. McMurry, M.P., Conner, W.E., and Cerqueira, M.T. (1982): Dietary cholesterol and the plasma lipids and lipoprotein in the Tarahumara Indians: a people habituated to a low cholesterol diet after weaning. Am. J. Clin. Nutr., 35, 741-744. 
4. Hegsted, D.M. (1986): Serum-cholesterol response to dietary cholesterol: a re-evaluation. Am. J. Clin. Nutr., 44, 299-305.

5. Thuesen, L., Henriksen, L.B., and Engby, B. (1986): One-year experience with a low-fat, low-cholesterol diet in patients with coronary heart disease. Am. J. Clin. Nutr., 44, 212-219.

6. Anderson, J.T., Grande, R., and Keys, A. (1976): Independence of the effects of cholesterol and degree of saturation of the fat in the diet on serum cholesterol in man. Am. J. Clin. Nutr., 29, 1184-1189.

7. Nestel, P.J. (1986): Fish oil attenuates the cholesterol induced rise in lipoprotein cholesterol. Am. J. Clin. Nutr., 43, 752-757.

8. Williams, P.T., Krauss, R.M., Kindel-Joyce, S., Dreon, D.M., Vranizan, K.M., and Wood, P.D. (1986): Relationship of dietary fat, protein, cholesterol and fiber intake to atherogenic lipoproteins in men. Am. J. Clin. Nutr., 44, 788-797.

9. Jackson, R.L., Kashyap, M.L., Barnhart, R.L., Allen, C., Hogg, E., and Glueck, C.J. (1984): Influence of polyunsaturated and saturated fats on plasma lipids and lipoproteins in man. Am. J. Clin. Nutr., 39, 589-597.

10. Stein, E.A., Shapero, J., McNerney, C., Glueck, C.J., Tracy, T., and Gartside, P. (1982): Changes in plasma lipid and lipoprotein fractions after alteration in dietary cholesterol, polyunsaturated, saturated, and total fat in free-living normal and hypercholesterolemic children. Am. J. Clin. Nutr., 35, 1375-1390.

11. Hirai, K., Ohno, Y., Nakano, T., and Izutani, K. (1984): Effects of dietary fats and phytosterol on serum fatty acid composition and lipoprotein cholesterol in rats. J. Nutr. Sci. Vitaminol., 30, 101-112.

12. Haddad, E., Blankenship, J.W., and Register, U.D. (1985): Short term effect of low fat diet on plasma retinol and $\alpha$-tocopherol and red cell $\alpha$-tocopherol levels in hyperlipidemic men. Am. J. Clin. Nutr., 41, 599-604.

13. Shitara, H., Uruno, K., Takahashi, Y., Maishi, S., and Kimura, S. (1976): Relationship between serum vitamin $\mathrm{E}$ levels and serum cholesterol in normal adults in rural regions of Yamagata Prefecture, Japan. J. Nutr. Sci. Vitaminol., 22, 101-104.

14. Lehmann. J., Marshall, M.W., Slover, H.T., and Lacono, J.M. (1977): Influence of dietary fat level and dietary tocopherol on plasma tocopherols of human subjects. J. Nutr., 107, 1006-1015.

15. Willett, W.C., Stampfer, M.J., Underwood, B.A., Speizer, F.E., Rosner, B., and Hennekens, C.H. (1983): Validation of a dietary questionnaire with plasma carotenoid and $\alpha$-tocopherol levels. Am. J. Clin. Nutr., 38, 631-639.

16. Horwitt, M.K., Harvey, C.C., Dahm, C.H., and Searcy, M.T. (1972): Relationship between tocopherol and serum lipid levels for determination of nutritional adequacy. Ann. NY. Acad. Sci., 203, 223-236.

17. Kaseki, H., Kim, E.Y., Whisler, R.L., and Cornwell, D.G. (1986): Effect of an oral dose of vitamin $\mathrm{E}$ on the vitamin $\mathrm{E}$ and cholesterol content of tissues of the vitamin $\mathrm{E}$-deficient rat. J. Nutr., 116, 1631-1639.

18. Harper, A.E. (1959): Amino acid balance and imbalance. Part I. Dietary level of protein and amino acid imbalance. J. Nutr., 68, 405-424.

19. The Japan Oil Chemists' Society (1977): Standard Method of Analysis of Fats and Oils, No. 2. 4. (in Japanese).

20. Hirai, K., Shimazu, C., Takezoe, R., and Ozeki, Y. (1986): Cholesterol phytosteol and polyunsaturated fatty acid levels in 1982 and 1957 Japanese diets. J. Nutr. Sci. Vitaminol., 32, 363-372.

21. Abe, K., and Katsui, G. (1975): Determination of tocopherols in serum by high speed liquid chromatography. Vitamin, 49, 259-263, (in Japanese).

22. Report of an expert consultation of the Food and Agriculture Organization of the United Nations and the World Health Organization (1977): Dietary fats and oils in human nutrition in FAO Food and Nutrition Paper, No. 3, Rome. 